\title{
Functional Outcomes of Internal Fixation of Complex Tibial Plateau Fractures: A Case Series
}

\author{
Dhrubajyoti Talukdar ${ }^{1}$, Pradip Kr. Baruah ${ }^{2}$, Rohit Ailani ${ }^{3}$, Sagar Tontanahal $^{4}$ \\ ${ }^{1,2,3,4}$ Dept of Orthopaedics, Gauhati Medical College and Hospital, Guwahati.
}

\begin{abstract}
Aim: To study the functional outcomes of internal fixation in complex tibial plateau fractures.

Materials and Methods: 51 patients presenting with complex tibial plateau fractures were treated between January,2013 to January,2016 with various modes of internal fixation depending on the fracture type. Subsequently the patients were followed up at 2,6,12,18 and 24 weeks and then at intervals of three months. Early mobilization was encouraged, and weight bearing was allowed on the basis of callus formation. The functional results were evaluated using the criteria of The Knee Society Clinical Rating System. Results: 18 patients of Schatzker type VI fractures were treated, out of which 9 were treated using only lateral plates, 7 were treated using lateral plates and additional cancellous screws, and 2 were treated using bicondylar plating. 15 patients of Schatzker type $V$ were treated, out of which 10 were treated using lateral lock plates and cancellous screw medially, 4 were treated using only lateral lock plates and 1 was treated with bicondylar plating. Remaining 18 patients of Schatzker type II,III,IV were treated using either only screws or lateral lock plates, buttress plates and screws with or without bone graft. The mean follow up was 1 year (range 10 months to 34 months). All patients were followed up, and their functional outcome was recorded.

Conclusions: Good results were obtained with internal fixation. There was good range of motion at the knee joint and excellent functional results.
\end{abstract}

\section{Introduction}

Proximal tibial fractures are important fractures involving one of the main weight-bearing joints whose serious injury results in movement and ability dysfunctions ${ }^{1}$. The main goal of the treatment of these fractures is to maintain the normal function of the knee joint, improve the joint instability, prevent lower limb malalignment and deformity, and prevent knee osteoarthritis ${ }^{2-4}$.

There are multiple treatment options for fixations of these fractures including screws, external fixator, hybrid external fixator ${ }^{5,6}$, limited internal fixation with a tensioned wire ${ }^{7}$, classical dual buttress plate, unilateral periarticular locking plate and hybrid dual plates (combination of locking plate and buttress plate). Unfortunately, there is no gold standard treatment approach for various types of tibial plateau fractures; therefore, different methods have been employed depending on the type of fracture. Both the complexity and the soft-tissue disruption of this subgroup of fractures contribute to the high rate of unsatisfactory results which follow surgical management ${ }^{8,9}$. The present prospective follow-up study evaluated the methods of fixation of closed tibial plateau fractures with different modalities of internal fixation in terms of long-term articular functional outcomes.

\section{Materials And Methods}

A prospective study was conducted to study the functional outcomes of tibial plateau fractures fixed with different modalities of internal fixation. The subjects were selected from patients suffering from closed tibial plateau fractures attending Guahati Medical College and Hospital, Guwahati, India from January, 2013 to January,2016. The following were the inclusion criteria for the study:

- Only those patients who gave consent.

- Age between 18 and 70 years.

- Closed tibial plateau fractures.

- Duration of injury < 3 weeks.

- Competent neurological and vascular status of the affected limb.

- Ipsilateral hip, knee, ankle and contralateral lower limb functionally good enough, so as not to exert a serious adverse effect on the rehabilitation process.

All fractures were classified according to the Schatzker classification ${ }^{10}$. An additional CT scan of the knee was advised if the fracture lines were not clearly delineated in the radiographs. The timing of surgery depended on the soft-tissue conditions. Femoral distractor aided in indirect reduction of the fracture fragments 
in two cases. The majority of depression of more than $5 \mathrm{~mm}$ needed an open reduction. The internal fixation was done according to the type of fracture using plates or screws, or both of these .Where possible, MIPO was performed where an anatomically contoured locking lateral proximal tibia plate was put through the anterolateral incision. Double plating (medial and lateral) was used in high energy fractures with a displaced coronal split component of the posterior aspect of the medial tibial plateau. In bicondylar fractures with major medial fragment, $6.5 \mathrm{~mm}$ cannulated cancellous screws were used as antiglide screws from the medial side percutaneously. Artificial bone graft ( hydroxyapatite) was used for tibial metaphyseal defects after elevation of depression more than $5 \mathrm{~mm}$, and in those with major comminution. Rehabilitation was started on the second postoperative day with quadriceps strengthening and assisted range of motion exercises.

Follow-up routine anteroposterior, and lateral radiographs were obtained at 6,12,18 \& 24 weeks and then every 3 months interval until clinical and radiological fracture union had been established. Tibial alignment in both planes was assessed according to Freedman and Johnson's description for determining the alignment of the tibial plateau, both on coronal plane (medial proximal tibial angle or MPTA) and sagittal plane (posterior proximal tibial angle or PPTA) $)^{11}$.

The knee society score (KSS) and a visual analog scale (VAS) for pain $(0=$ no pain; $10=$ worst imaginable pain) for the rest/loaded condition were obtained from all patients during the last consultation. Functional outcomes in ten months were assessed using the Knee Society knee score that considers a clinical score (including pain, stability, range of motion, flexion contracture, extension lag, and malalignment) and a functional score (that assesses walking distance and stair climbing ${ }^{12}$. This score was graded as excellent (80 to $100)$, good (70 to 79), fair (60 to 69), and poor (below 60) $)^{13}$.
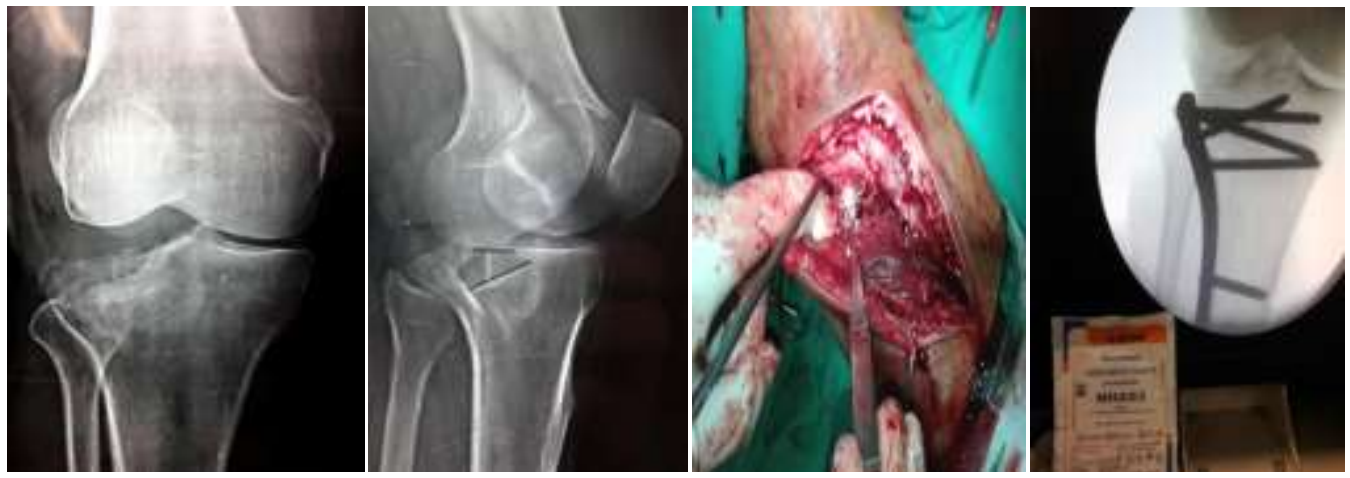

CASE 1: Type II Schatzker with significant depression: elevation and bone grafting
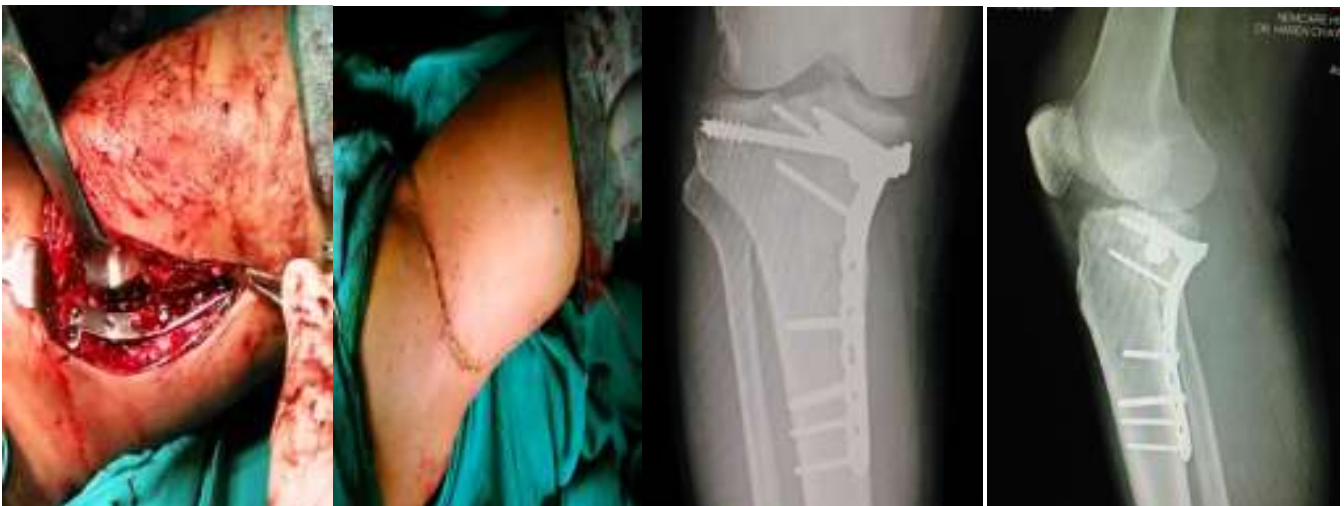

CASE 2: Posteromedial approach with patient in prone position

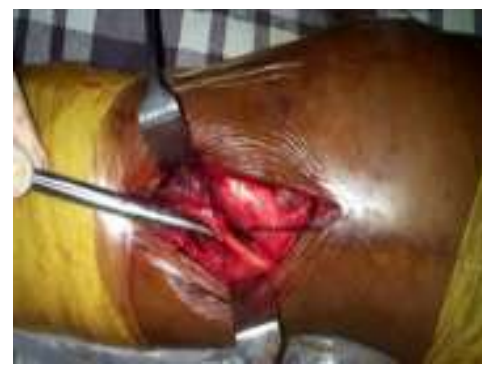

CASE 3: Posterolateral approach

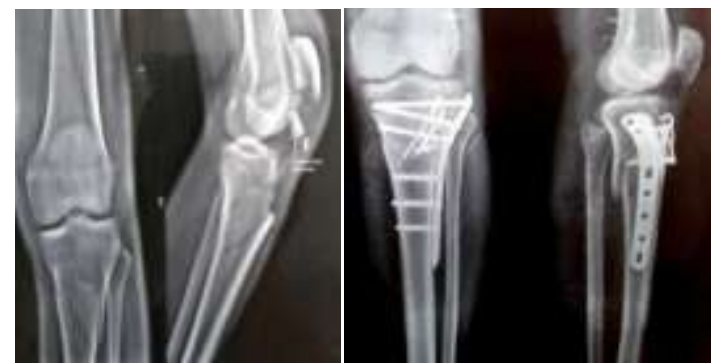

CASE 4: Associated tibial tuberosity avulsion 


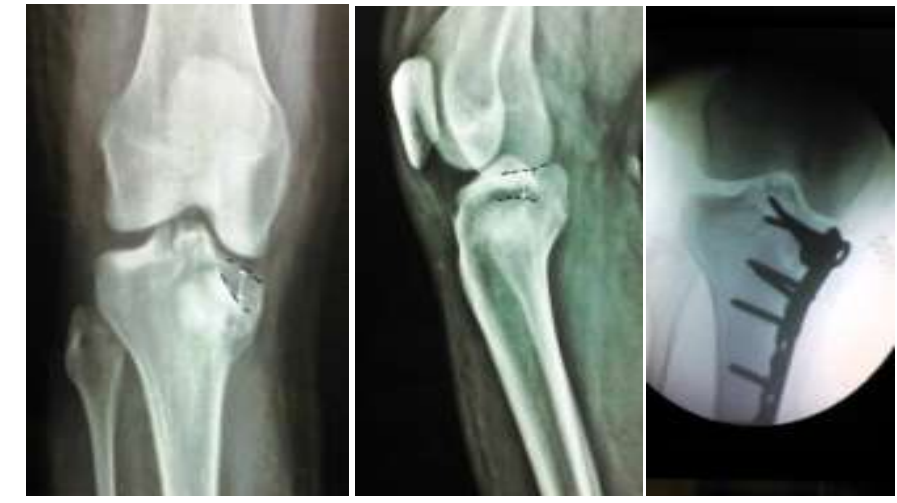

CASE 5: Dual plating through posteromedial approach

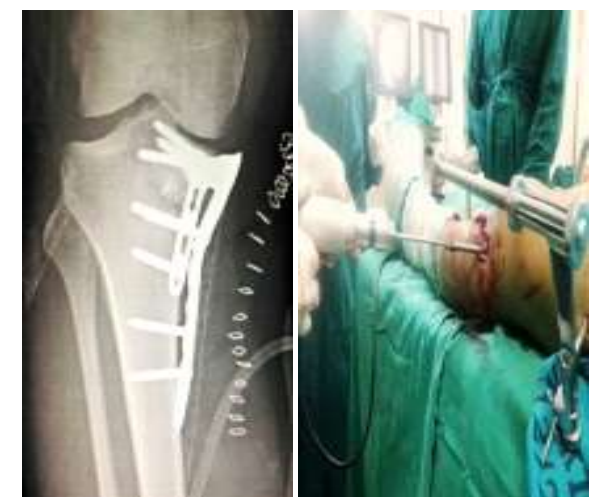

CASE 6: Indirect reduction by femoral distractor
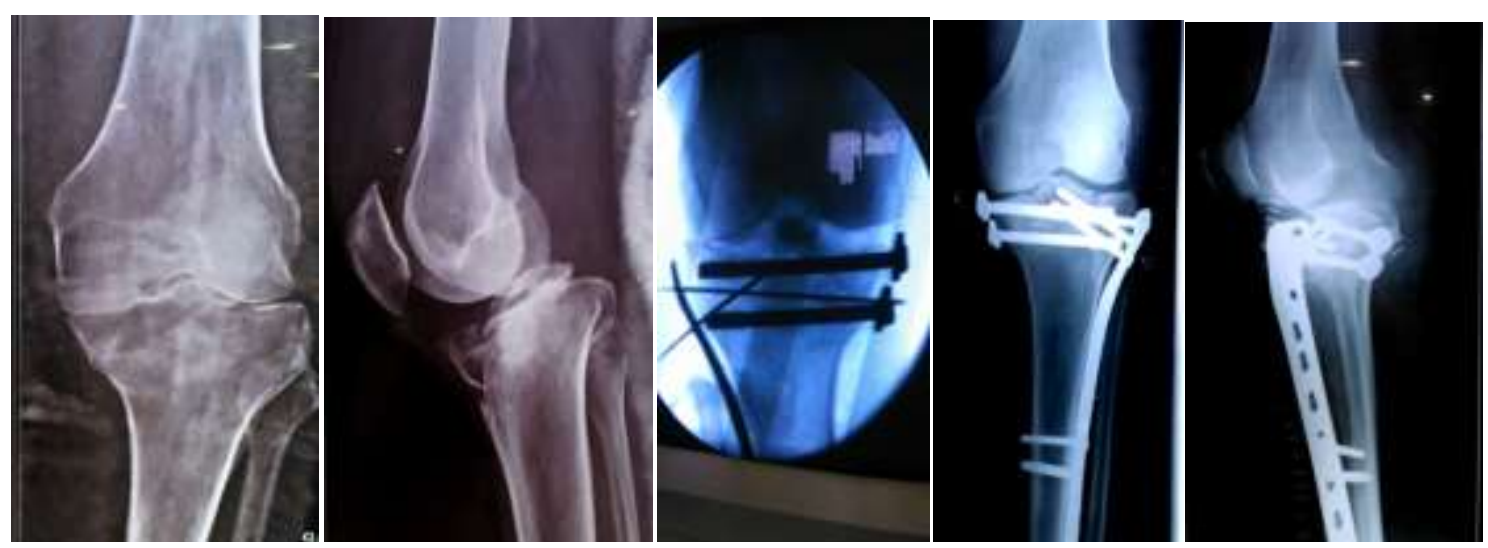

CASE 7: Type V Schatzker: reduction held by k-wires,mediolateral $6.5 \mathrm{~mm}$ cannulated screws put percutaneously with the proximal tibial locking plate fixed by MIPO technique laterally.

\section{Results}

51 patients were assessed for the minimum period of 10 months. There were 35 male patients and 16 female patients. The mean age was 46.34 years(range 18-70).18 patients had Schatzker type VI fratures ,15 patients had Schatzker type V fractures ,remaining 18 patients had either Schatzker type II,type III,or type IV. 2 patients had associated ACL injury, 5 had MCL injury and 1 patient had associated tibial tuberosity avulsion fracture.

\section{KSS clnical outcome:}

This includes patient knee range of motion, extensor lag, flexion contracture and instability. The average knee flexion was around 120 degrees( average 0 to 130degrees),however three patients had restriction of flexion of less then 100 degrees. Five of our patients had minor extension limitation (range 5 to 15 degrees) .One patient had 15 degrees of flexion deformity which was treated by manipulation under general anaesthesia. Two patients had detectable residual MCL instability while one patient had lateral collateral ligament instability initially which later improved.

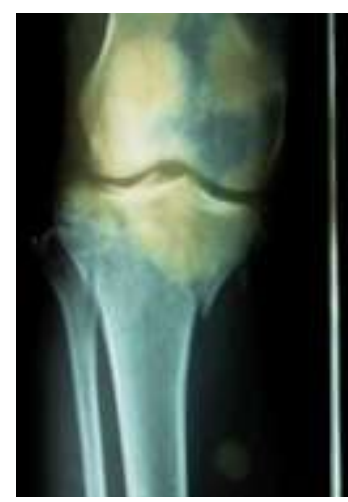

DOI: $10.9790 / 0853-1507105764$
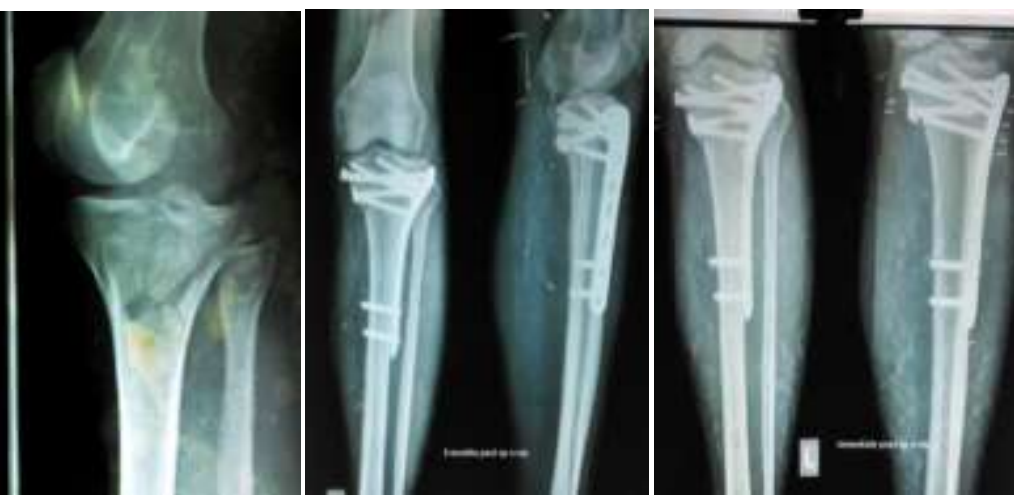

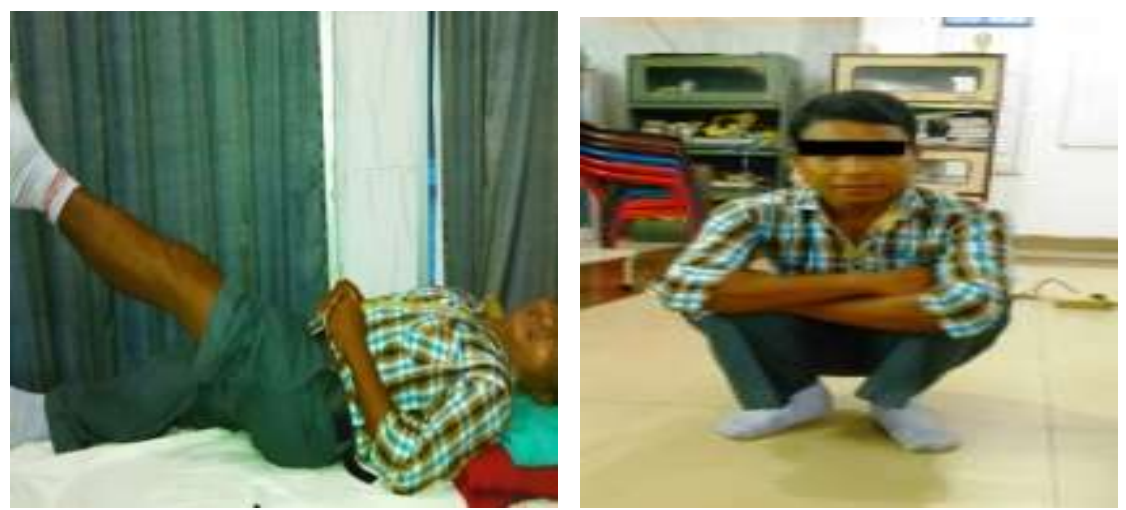

CASE 1: Type VI Schatzker fixed with additional mediolateral screws : 8 months post op
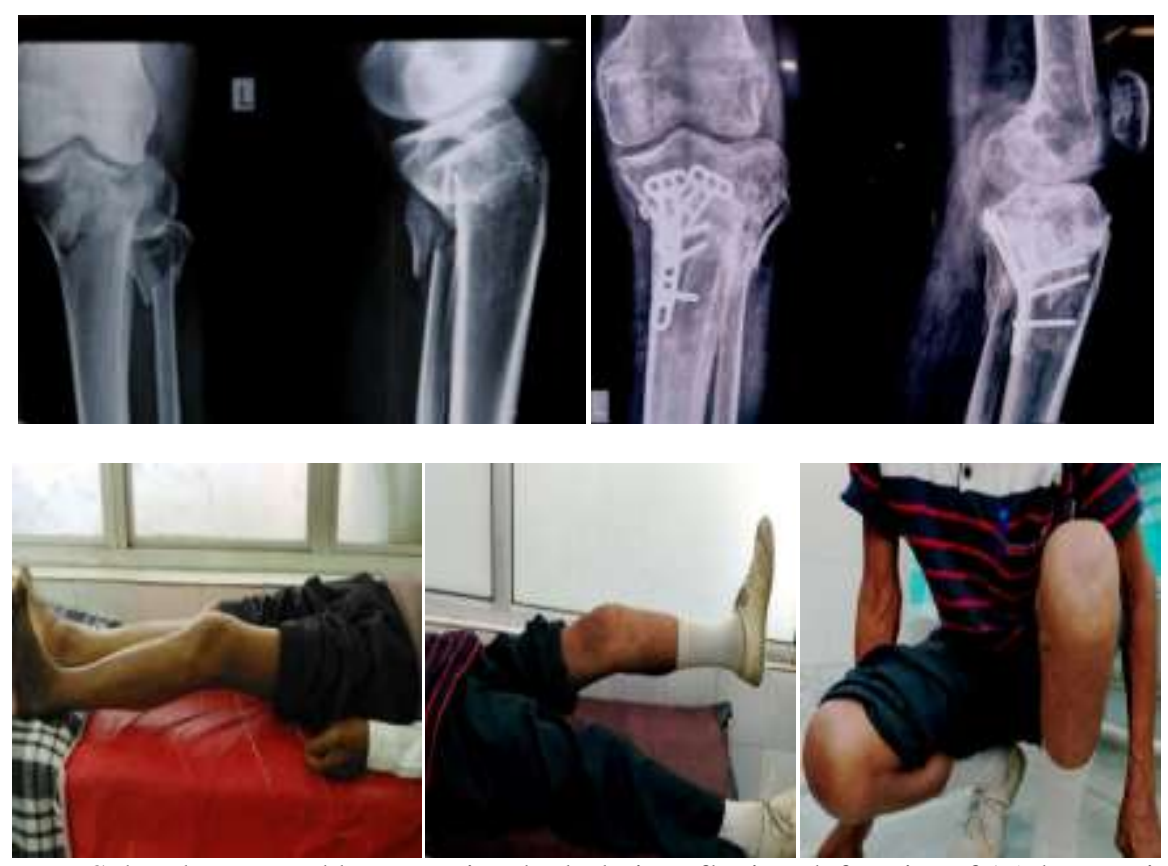

CASE 2: Type VI Schatzker treated by posterior dual plating: flexion deformity of 15 degrees improved after manipulation under general anaesthesia.

\section{KSS radiological outcome:}

This includes alignment of the knee joint measured in AP standing $\mathrm{x}$ ray. All of our patients have neutral alignment of the knee except 3 patients who developed slight varus malalignment following fixation with a single anatomically contoured plate, or a low-profile buttress plate; another patient had lateral joint collapse $(<10$ degrees).This patient also had lateral condylar widening due to malreduction in immediate post operative radiograph. Other parameters were also observed like tilt, articular step, condylar widening, joint space. One patient with a coronal split fracture of the lateral condyle with a posterior fragment, treated by low profile buttress plate through posterolateral approach had both condylar widening and articular depression of more than $2 \mathrm{~mm}$.
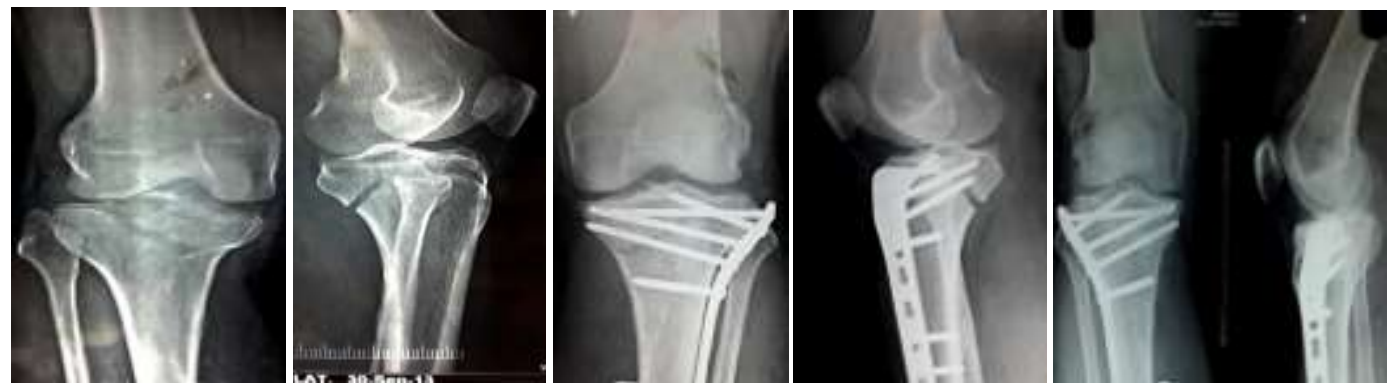

Picture 1: Type V Schatzker with posteromedial fragment. Excellent radiological picture after 33 months 

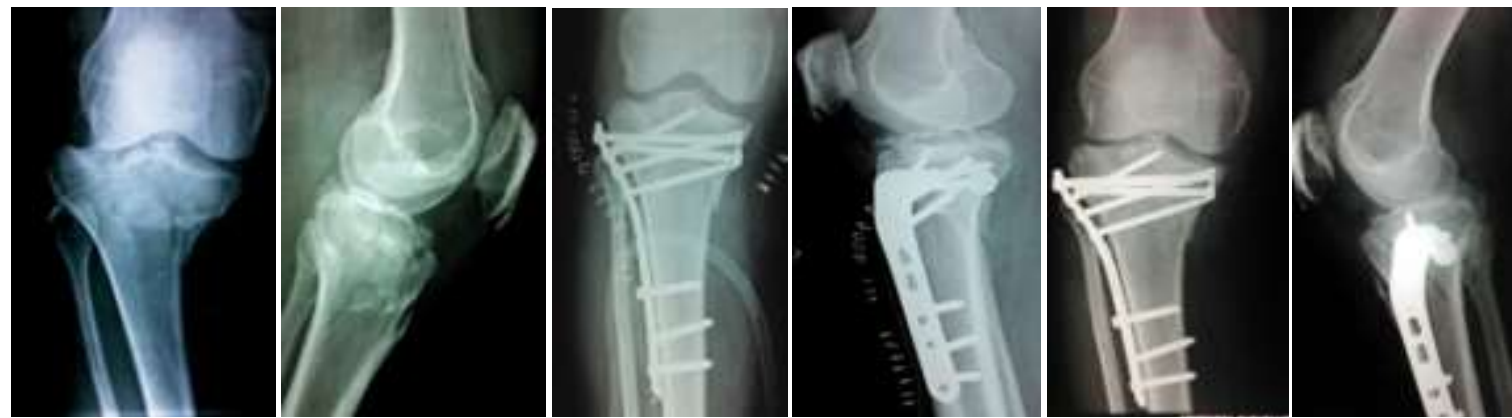

Picture 2: Pre-op X-Ray Immediate Post-op Xray Persistent varus malalignment at 6 months

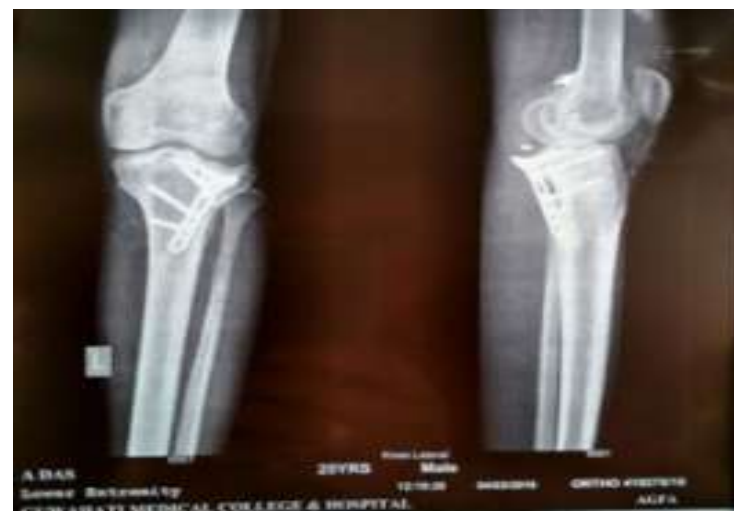

Picture 3: Condylar widening and articular depression at 7 months Post op.

\section{KSS functional outcome:}

All patients had excellent walking activity without any support after minimum period of 10 months.46 of our patients could walk for more than an hour without any support while 2 of the patient could walk for more than an hour but require support of a cane after some point of time. 30 patients are not bothered in standard and advanced activities of daily living like squatting, kneeling and climbing stairs.14 patients showed slight to moderate difficulty, 5 patients showed very severe difficulty while 2 patients could not do their standard and functional activities not because of pain but because of restriction of movement of knee joint. Our patients started walking without any aid at an average period of around 5.58 months from surgery(range 4-6 months) and all patients returned to their job at an average period of around 5 months from surgery(range 3-10 months).
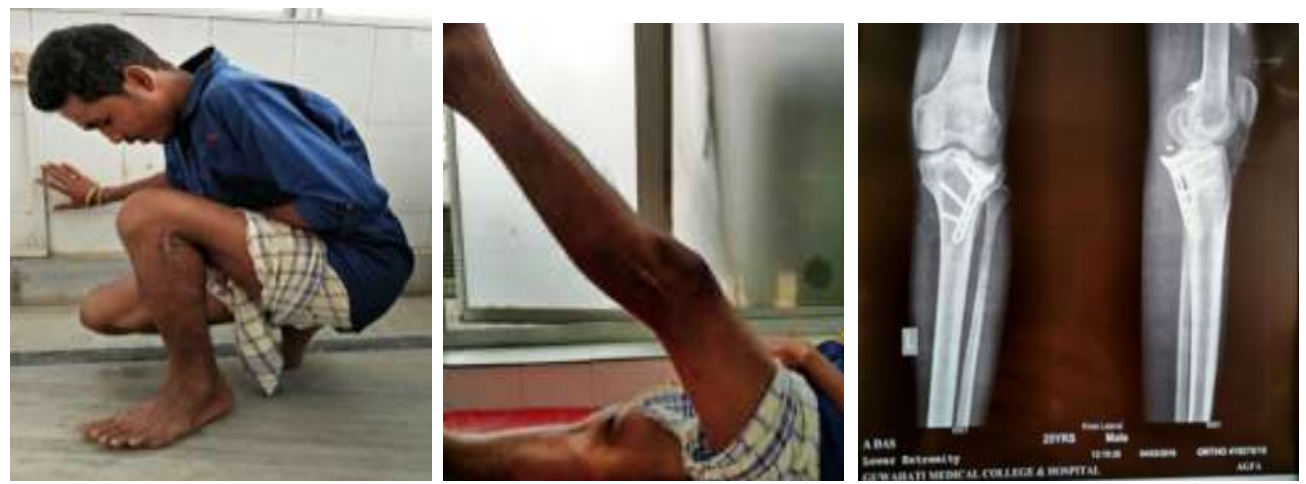

Picture: Good functional outcome at 7 months inspite of condylar widening and articular depression

KSS subjective outcome: Forty four of our patients do not complain of any pain while walking on the level ground or while climbing stairs or inclination ,only 5 patients complained of slight increase in pain while walking upstairs .Forty six of our patients are very satisfied with the pain level while sitting ,lying in bed, getting out of bed, performing light household activities or doing recreational activities, while 3 of them were only satisfied to neutral in their activities and 2 were dissatisfied mainly because of restriction of movement of the operated knee. The mean Knee Society Score at the time of latest follow up was 91(70-100)points, and the mean functional score was 89(54-100). 


\section{Complications}

There was one major complication in our study. One patient, who had presented with skin blisters and significant swelling, had extensive post-operative skin necrosis in second week. She required a gastrocnemius rotation flap for exposed plate following sloughing of skin and subcutaneous tissues six weeks after her first operation. 3 patients showed low grade infection two weeks post-operatively; 2 of them underwent incision and drainage and infection resolved with antibiotic therapy, and the third patient responded to oral antibiotics alone. 1 patient showed seroma and was treated by incision, drainage and antibiotics. One of our patients showed screw back-out, sloughing of the overlying skin making it exposed, and deep infection which required early removal of the implant. A prominent lateral plate was seen in two patients, which was not causing any clinical problem. 1 case of non-union was reported in our case series. Three patients had varus malalignment of more than 5 degrees. Three patients had an increase in articular angulation in the sagittal plane of 6 degrees ( range 4 to 8 degrees).All of them had an apex posterior angulation. There was one case of loss of reduction. Two patients had condylar widening of less than $5 \mathrm{~mm}$. None of our patient showed peroneal nerve palsy, deep vein thrombosis, haematoma formation or required fasciotomies.

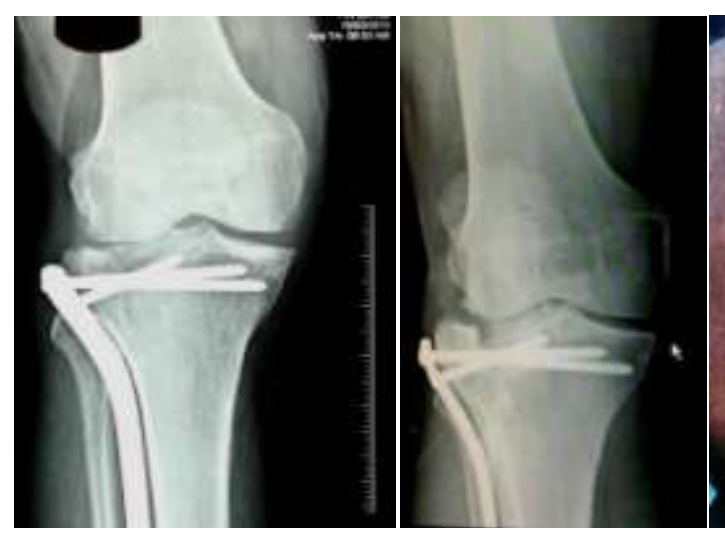

Non-union

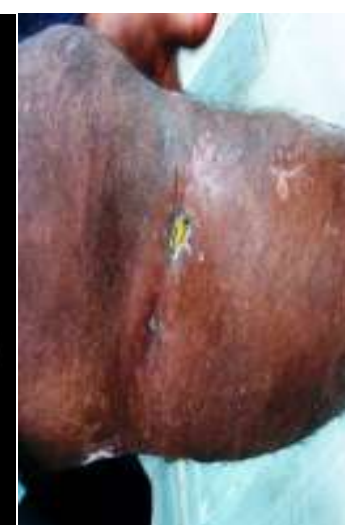

Superficial infection

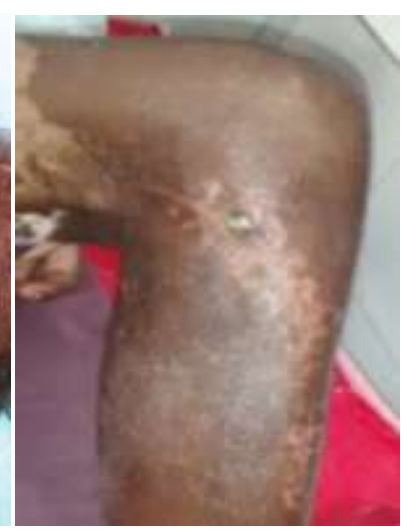

Screw backout

\begin{tabular}{|l|l|l|}
\hline${\text { Sven Mardian et } \mathrm{al}^{25}}^{25}$ & $6 \%$ & 2 deep infection \\
\hline Jackson A Lee et al $^{26}$ & $8 \%$ & 2 deep infection \\
\hline Coles PA et al $^{27}$ & $7.8 \%$ & $\begin{array}{l}2 \text { deep infection } \\
1 \text { superficial infection } \\
3 \text { seroma }\end{array}$ \\
\hline Kulkarni SG et al & & 2 superficial infection \\
\hline Koval et al $^{29}$ & $5.3 \%$ & 0 \\
\hline Present series & $0 \%$ & $\begin{array}{l}1 \text { deep infection } \\
\text { 3 superficial infection } \\
1 \text { seroma }\end{array}$ \\
\hline
\end{tabular}

\section{Discussion}

Tibial Plateau fractures are high energy injuries, often presenting with comminution and significant soft tissue damage. The principle of early mobilization by quadriceps strengthening and flexion exercises for the knee followed by protected weight bearing has revolutionized the treatment of tibial plateau fractures (Apleys 1956) ${ }^{14}$. Non operative treatment options are now restricted to undisplaced fractures that allow early partial weight bearing and functional exercises ${ }^{15}$.

Open anatomic reduction followed by stable internal fixation remains the gold standard for intraarticular fractures ${ }^{16}$; but stable fixation without compromising the soft tissue envelope is often difficult. A precontoured anatomically shaped locking compression plates can be inserted with a minimally invasive technique; it can also simultaneously achieve fixation of an associated metaphyseal or diaphyseal component of the fracture, and biomechanically it has a elastic deformation equal to that of conventional dual plates(lateral buttress and medial antiglide constructs $)^{17}$.Thus for the treatment of complex tibial plateau fractures ,the preferred surgical approaches have been the antero-lateral single incision,and anteromedial/posterolateral incisions for easier reduction of fractures and better wound healing ${ }^{18,19,20}$.

Maintenance of axial alignment is difficult in high energy fractures treated with a single lateral fixation; consequently there is the potential for malalignment (varus deformity/increased posterior tilt) ${ }^{21}$. The traditional lateral plating system offers little resistance to varus deformity; thus adjuvant medial neutralization plating has been advocated to increase stabilisation in fracture patterns with metaphyseal comminution. Immediate post operative and delayed loss of alignment in Schatzker type V and VI fractures have been reported when treated with laterally placed LISS plate only ${ }^{22,23}$. Ratcliff et al with their cadaveric biomechanical study 
showed that in the setting of a vertically oriented fracture in a medial tibial plateau without comminution, the medial buttress plate provides significantly greater stability in static loading and improved stability with cyclic loading in comparison with a single lateral locking plate stabilization.

Pernaa $\mathrm{K}$ et $\mathrm{al}^{24}$ stated that fracture displacement ranging from 4-10 $\mathrm{mm}$ can be treated non operatively; however a depressed fragment greater than $5 \mathrm{~mm}$ should be elevated and grafted. We have not encountered any subsidence following elevation and packing of metaphyseal voids by artificial bone grafting blocks and granules. None of our patients who did have bone grafting, also had any vertical displacement (subsidence) of articular fragment.

Post operative malalignment recorded in our series were due to inaccurate closed reduction prior to putting the anatomically contoured plate by minimally invasive technique, and failure to detect mal reduction in intraoperative radiograph. Both of these have been mentioned in the literature along with the surgeons familiarity and experience with closed reduction and MIPO technique for high incidence of malalignment and malreduction $^{31,32,33}$.

Like many other series we also faced some limitations while carrying out this study. We have a relatively small patient group; additionally, there are studies that propose that the incidence of post traumatic degenerative osteoarthritis following intraarticular fractures of the knee tends to develop later(average six to eight years after injury $)^{34}$.Patients with mal alignment of more than 5 degrees develop moderate to severe grade of osteoarthritis. Our series had only one radiologically evident secondary osteoarthritis in the lateral side after fourteen months of surgery, thus a short period of follow up is not sufficient to evaluate the long term results.

\section{Conclusion}

Unilateral locked screw plating is a good alternative for treatment of complex fracture of the tibial plateau that are associated with soft tissue damage and metaphyseal comminution. In bicondylar fractures, additional medio-lateral screw fixation improves stability and probably can reduce the need of an additional small fragment plate. The reduction technique for exact alignment is demanding. The postoperative radiographic articular congruity doesnot appear to predict clinical outcome at medium term follow up. Stable internal fixation without significant mal-alignment, and early mobilisation of the joint significantly improves overall clinical outcome.

\section{References}

[1]. D. Schneidmueller, E. Gercek, M. Lehnert, F. Walcher, and I. Marzi "Proximal tibial fractures," The American Journal of Sports Medicine, vol. 31, pp. 404-407, 2011.

[2]. M. Bhandari, L. Audige, T. Ellis et al., "Operative treatment of extra-articular proximal tibial fractures," Journal of Orthopaedic Trauma, vol. 17, no. 8, pp. 591-595, 2003.

[3]. S. G. Agnew, "Tibial plateau fractures," Operative Techniques in Orthopaedics, vol. 9, no. 3, pp. 197-205, 1999.

[4]. S. N.Maripuri,P.Rao,A.Manoj-Thomas, andK.Mohanty "The classification systems for tibial plateau fractures: how reliable are they?" Injury, vol. 39, no. 10, pp. 1216-1221, 2008.

[5]. Ali AM, Yang L, Hashmi M, Saleh M. Bicondylartibial plateau fractures managed with the Sheffield Hybrid Fixator. Biomechanical study and operative technique .Injury 2001;32:86-91.

[6]. Cole P, Levy B, Schatzker J, Watson JT. Tibial Plateau fractures. In Skeletal Trauma: Basic Science Management \& Reconstruction: Saunders Elsevier 2009:2201-2287.

[7]. Canadian Orthopaedic Trauma Society. Open Reduction and Internal Fixation Compared with Circular Fixator Application for BicondylarTibial Plateau Fracture. Results of Multicentric, Prospective Randomized Clinical Trial. J Bone Joint Surg Am 2006;88:2613-23.

[8]. Blokker CP, Rorabeck CH, Bourne RB. Tibial Plateau Fractures: An Analysis of the Results of Treatment in 60 Patients. ClinOrthopRelat Res1984;182:193-199.

[9]. Ali AM, Burton M, Hashmi M, Saleh M. Outcome of Complex Fractures of the Tibial Plateau Treated with a Beam-Loading Ring Fixation System. J Bone Joint Surg(?) 2003;85(5):691-699.

[10]. Schatzker J, McBroom R, Bruce D. The tibial plateau fracture.The toronto experience 1968-1975. Clin Orthop Relat Res1979;138:94- 104

[11]. E. L. Freedman and E. E. Johnson, "Radiographic analysis of tibial fracture malalignment following intramedullary nailing" Clinical Orthopaedics and Related Research, no. 315, pp. 25-33,1995.

[12]. J. N. Insall, L.D.Dorr, R. D. Scott, andW.N. Scott"Rationale ofThe Knee Society clinical rating system,” Clinical Orthopaedics and Related Research, no. 248, pp. 13-14, 1989.

[13]. S. Asif and D. S. Choon, "Midterm results of cemented Press Fit Condylar Sigma total knee arthroplasty system," Journal of Orthopaedic Surgery, vol. 13, no. 3, pp. 280-284, 2005.

[14]. Apley AG Fractures of lateral tibial condyle treated by skeletal traction and early mobilization:a review of sixty cases with special reference to the long term results. J Bone Joint Surgery[Br]1956:38-B:699-708

[15]. Bono CM,Levine RG,Rao JP,Behrens FF.Nonarticular proximal tibial fractures:treatment options and decision making. J Bone Joint Surgery.2001;9:176-86(Pubmed)

[16]. Marsh JL,Smith ST,Do TT.External fixation and limited internal fixation for complex fractures of the tibiaal plateau.J Bone Joint Surgery Am.1995;77:661-73(Pubmed)

[17]. Gosling T,Partenheimer A,Krettek C(2004)Less invasive stabilisation of complex tibial plateau fractures a biomechanical evaluation of a unilateral locked screw plate and double plating .Journal of orthopaedic trauma 18:546-551(Pubmed)

[18]. Waddel JP,Johnston DW,Neidre A. Fractures of the tibial plateau :a review of ninety five patients and comparison of treatment methods. J. trauma 1981:21:376-381 
[19]. Marsh JL.Tibial plateau fractures. In:Bucholz RW, Heckman JD,Court-Brown CM Tornetta PIII,editors.Rockwood and Greens fracture in adults. $7^{\text {th }}$ edition .Philadelphia ,PA:Lippincott Williams\&Wilkns;2009:1780-1831.

[20]. Tejwasi NC, Hek DJ, High energy proximal tibial fractures:treatment options and decision making .Instr course lect 2006:55:367379(Pubmed)

[21]. Waddell JP,Johnston DW,Neidre A. Fractures of the tibial plateau :a review of ninety five patients and comparison of treatmen methods. J trauma.1981;21:376-381.

[22]. Phisitkul P,Mc kinley T,Nepola JV,Marsh JLJ orthopaedic Trauma. 2007 Feb;21(2):83-91(Pubmed)

[23]. Single lateral locked screw plating of bicondylar tibial plateau fractures.Gosling T,Schandelmaier P,Muller M,Hankemeier S, wagner M,Kretttek C. Clinical orthopaedic Rel Res 2005 Oct;439:207-14

[24]. Pernaa K,Koski S,Aho A,et al.Bioactive gass S53P4and autograft bone in treatment of depressed tibial plateau fractures.A prospective randomised 11 year follow up.J Long Term Eff Med Implants.2011.21(2):139-48(Medline)

[25]. Sven Mardian, Felix Landmann, Floria Wichlas,Norbert Phaas,Klaus-Dieter Schaser,Philipp Schwabe.Indian Journal of orthopaedics.2015 Nov-Dec;49(620-629)

[26]. Jackson A.Lee,Stamatios A. Papadakis,Charles Moon, Charalampos G. Zalavros.tibial plateau fracture treated with the less invasive stabilisation system Int Orthpaedics.2007 Jun;31(3):415-418.

[27]. Cole PA,Zlawodzki M,Kregor PJ(2004).Treatment of proximal tibia fractures using the less invasive stabilisation system:surgical experience and early clinical results in 77 fractures .J orthopaedic Trauma 18:528-535(Pubmed)

[28]. Kulkarni SG, Tangirala R,Malve SP, Kulkarni MG.Kulkarni VS, Kulkarni RM, Kriplani S. Use of a raft construct through a locking plate withut bone grafting for split- depression tibial plateau fractures.Journal of Orthpaedic Surgery 2015;23(3):331-5

[29]. Koval KJ,Sanders R,Di Pasquate T,Mast JW.J Orthopaedic Trauma,192;6(3):340-6.Indirect reduction and percutaneous screw fixation of displaced tibial plateau fractures .

[30]. Jackson A.Lee,Stamatios A. Papadakis,Charles Moon, Charalampos G. Zalavros.Tibial plateau fracture treated with the less invasive stabilisation system Int Orthpaedics.2007 Jun;31(3):415-418.

[31]. Cole PA,Zlawodzki M,Kregor PJ(2004).Treatment of proximal tibia fractures using the less invasive stabilisation system:surgical experience and early clinical results in 77 fractures .J orthopaedic Trauma 18:528-535(Pubmed)

[32]. Phisitkul P,Mc kinley To,Nepola JV,Marsh JL,J orthopaedic Trauma. 2007 Feb;21(2):83-91(Pubmed)

[33]. Gosling T,Schandelmaier P,Muller M,Hankemeier S, wagner M,Kretttek C. Single lateral locked screw plating of bicondylar tibial plateau fractures;Clinical orthopaedic Rec Res 2005 Oct;439:207-14

[34]. Manidakis N,Dosani A,Dinitriou R,Stengel D,Matthews S,Gannoudis P. Tibial plateau fractures functional outcome and incidence of osteoarthritis in 125 cases.Int Orthopaedic 2010;34:56 